\title{
Editorial
}

\section{A Deserving Winner}

The competition for the first William Bynum Prize 2013 was intense; four of the papers submitted for consideration have been deemed worthy of publication on the basis of a demanding peer review process. Our Prize Committee, which consisted of five inspirational colleagues who consistently sacrificed a lot of their time despite having busy work-schedules, included Dr Jeremy Greene of Johns Hopkins University, USA; Professor Colin Jones, Queen Mary, University of London, UK; Professor Amarjit Kaur, University of New England, Australia; Professor Magali Sa, Fiocruz, Rio De Janeiro, Brazil, and Professor William Bynum himself. Having considered the views of all these colleagues carefully, Professor Bynum, who served as the Chair of the Prize Committee, is delighted to announce Dr Andrew J. Hogan, a lecturer in Science, Technology, and Society at the Department of Engineering and Society, University of Virginia, USA, as a worthy winner. Andrew's paper, titled 'The "Morbid Anatomy" of the Human Genome: Tracing Observational Approaches in Postwar Genetics and Biomedicine, 1970-1989', was widely lauded for the quality of research and analysis, and will appear as the lead article in the summer 2014 issue of Medical History. Professor Bynum also announced the names of two other candidates as joint runners-up: Dr Katherine Walker, who completed her PhD from McMaster University in Canada in 2011, and Ms Darshi Thoradeniya, who has just completed her doctoral thesis at Warwick University, UK. We, at Medical History, would like to congratulate these outstanding young scholars for their excellent work.

I would also like to thank the committee members and the colleagues who acted as referees for all the submitted papers for their energy and time, and Dr Alexander Medcalf, the Assistant Editor of this journal, for his care in dealing with the prize submissions and all external correspondence regarding these pieces of work. I would also like to record my appreciation for Cambridge University Press, for instituting the William Bynum Prize and supporting it so generously. Finally, I would like to remind our readers that the competition for the William Bynum Prize 2014 is now open and we encourage eligible candidates to send us their submissions. Information about the rules can be accessed through the journal website.

\section{SANJOY BHATTACHARYA}

Department of History, and Centre for Global Health Histories, University of York, UK

Email: sanjoy.bhattacharya@york.ac.uk 